\title{
MUTILACIÓN GENITAL FEMENINA EN ÁFRICA: MOOLAADÉ (2004) DE OSMANE SEMBÈBE
}

\author{
David Almazán Tomás
}

Universidad de Zaragoza

Isabel Ortega Sánchez

Universidad de Zaragoza

\section{OUSMANE SEMBÈNE, UN GRIOT EN EL ÁFRICA POSTCOLONIAL}

En general nuestros conocimientos sobre la cultura africana son deficientes y llenos de prejuicios $^{1}$. Si bien es cierto que en el panorama cinematográfico, ya desde hace tiempo, el mapa de la historia del cine ha ido ampliándose hacia «otras» cinematografías, como el cine asiático o latinoamericano, lo cierto es que en el caso del cine africano sigue injustamente fuera de plano. En este contexto, la excepcional figura del novelista y director de cine senegalés Ousmane Sembène (1923-2007) ofrece un inmejorable punto de arranque para iniciarse en la cinematografía africana. No es exagerado afirmar que Sembène no sólo es el padre del cine africano, sino que sin duda es uno de los mejores cineastas de todos los tiempos, con una producción coherente y sumamente interesante para analizar el África postcolonial, desde una posición comprometida política y socialmente ${ }^{2}$. Ousmane Sembène se proclama testigo y narrador de la lucha heroica diaria de mujeres y hombres africanos por transformar la sociedad africana y liberarla de las guerras, las injusticias y las desigualdades. Con acierto, Françoise Pfaff se ha referido a Sembène como un griot de los tiempos modernos (Pfaff, 1995)

1 Esto es consecuencia del desencuentro histórico entre Europa y África, la visión negativa de lo africano que se proyecta desde los medios de comunicación y la persistencia del eurocentrismo en nuestro sistema educativo. Sobre esto último, basta con examinar la ausencia de África en los planes de estudios de las titulaciones de nuestras universidades, que en general son impermeables a la riqueza e interés de su arte, su literatura, pensamiento, música, danza, etc. También en el cine esto es así.

2 Entre los numerosos estudios sobre este cineasta, destacamos los imprescindibles estudios de Samba Gadjigo y Françoise Pfaff, una selección de los cuales se proporcionan en la bibliografía final, así como las propias entrevistas a Sembène, recientemente recopiladas por Buuch y Annas. 
adaptado a los nuevos medios técnicos, idea que ha sido reconocida por el propio cineasta en numerosas ocasiones. Como un griot ${ }^{3}$ actualizado, ha dirigido su capacidad de contar historias hacia novelas y películas, sirviéndose del cine para transmitir nuevos mensajes. De este modo, ha logrado difundir un discurso comprometido con la emancipación de África, superando los límites de la transmisión oral tradicional. Los recursos de la tradición oral de los griots reaparecen con maestría en la obra de Sembène (Cham, 1982), quien en ocasiones los incorpora en sus películas, bien ocupando el lugar del narrador, bien con la presencia de griots en la propia trama, generalmente en torno a una asamblea o una celebración. Sembène siempre ha sido consciente de la importancia de la imagen, del cine, de la televisión, como vehículos de transmisión de la cultura. Del mismo modo, la potencia de estos nuevos medios tecnológicos tiene el peligro de extender modelos sociales, modos y costumbres desde la acción de un neocolonialismo que debilita valores tradicionales africanos. Desde una posición crítica anticolonial, como hombre de acción, sindicalista y activista afiliado al Partido Comunista francés, Sembène decidió amplificar su obra literaria como novelista mediante el cine, con el fin de lograr mayores audiencias en el continente africano. Para ello se formó en Moscú, en la Escuela de Cine Gorki, en 1961. Desde sus primeros trabajos, muestra una extraordinaria capacidad para fusionar un sólido lenguaje visual cinematográfico y la tradición oral africana en la transmisión de historias que enfocan la opresión que sufren los estratos sociales menos favorecidos, sin renunciar a cierto preciosismo estético que resalta la belleza de lo africano. Su mirada denuncia la compleja situación de África tras la colonización. En coherencia con su ideología marxista, sus películas hacen un recorrido por los diferentes tipos de opresión basados en las desigualdades de etnia, raza, género, edad, clase social, educación, geográficas, culturales, etc. En este sentido, podemos ver en sus películas un recorrido por los diversos ejes identitarios en torno a los cuales se estructuran las diferencias sociales. La dominación y la explotación se configuran como hilo conductor de toda su filmografía. Creados y dirigidos por Sembène, sus personajes ejecutan una danza que representa el difícil equilibrio en que se encuentra la población africana. Desestructurada su cultura tradicional por los efectos del colonialismo, el postcolonialismo y el neocolonialismo, las instituciones tradicionales basadas en la solidaridad se tambalean en pugna con el sistema económico que se insertó durante el periodo colonial y con la explotación de las diferencias económicas Norte-Sur. Son películas dirigidas al público africano, muchas veces rodadas en lenguas africanas y desde la convicción de que el cine es una herramienta para el cambio social y político y no una simple industria para el entretenimiento. Desde su primer largometraje, La Noire de... (1966) su cine ha descrito la necesidad de encontrar la identidad africana tras la colonización, ha denunciado los abusos militares franceses en Senegal durante la dominación colonial (González, 2009: 11-33) en comprometidas películas como Emitaï (1971) y Le Camp de Thiaroye (1987) y ha presentado las tensiones vitales y contradicciones de la descolonización y la burocracia en obras maestras como Mandabi (1868) y Xala (1974). También la complejidad del mosaico religioso africano (el Islam, el Cristianismo y eso que denominamos animismo, esto es, las religiones autóctonas) ha sido uno de los ejes de la producción de Sembène, especialmente en películas como la polémica Ceddo (1977), centrada en el conflicto cultural derivado de la

3 Se le da el nombre genérico de griot o jeli, al recitador de historias profesional que mantiene en su memoria la tradición oral y la transmite a la comunidad. Su repercusión cultural en el África Occidental (Senegal, Malí, Guinea, Mauritania, etc.) como bibliotecas vivientes que conservan las leyendas, la literatura y la historia es de una importancia sobresaliente. 
expansión del Islam por África occidental y su repercusión en la prohibición de los cultos animistas y costumbres locales de los distintos grupos étnicos, especialmente en grupos matrilineales. En Gelwaar (1992) con la denuncia sobre la corrupción política como telón de fondo, Sembène reflejó el enfrentamiento religioso entre dos comunidades derivado de un error al enterrar en un cementerio musulmán a un cristiano al que se quiere exhumar. En toda esta temática, propia de la cultura postcolonial africana, se entrecruza y sobresale la situación de la mujer como sujeto oprimido.

\section{VÍCTIMA Y HEROÍNA: LA MUJER AFRICANA EN LA FILMOGRAFÍA DE SEMBÈNE}

Entre los desposeídos y marginados por la sociedad postcolonial, Sembène se preocupa por la situación particular de la mujer africana, que sufre la doble marginación derivada de la acción combinada del colonialismo externo y el yugo interno de la tradición africana. Por esto, la figura de la mujer siempre ha tenido cierta relevancia tanto en la literatura como en la filmografía de Sembène (McCaffrey, 1980, Rufa'i, 1983 y Makward, 1991). En La Noire de... (1966), metáfora del racismo europeo, la protagonista es una elegante senegalesa contratada como empleada de hogar para trabajar en Francia que acaba suicidándose por el trato indigno que recibe. En otros trabajos rodados en la década de los setenta se aprecia el importante papel de la mujer en el mantenimiento de la identidad cultural y la dignidad ante elementos foráneos (Kindem y Steele, 1991: 52-60). De este modo, en Emitaï (1971), el grupo de las mujeres de una aldea diola representa la resistencia a la confiscación de la cosecha de arroz por parte de las tropas coloniales de tirailleurs al mando de oficiales franceses. En Ceddo (1977), una princesa raptada por una aldea que no quiere convertirse al Islam es finalmente quien da muerte al imán que pone en peligro las instituciones tradicionales. Por otra parte, en otras películas, la mujer aparece con frecuencia limitada al rol de esposa ilustrando la costumbre de la poligamia (Diop, 1985 y ljere, 1988). Este tipo de matrimonio, muy extendido en África marca las relaciones de parentesco en las tramas argumentales. Las relaciones entre las esposas se caracterizan por el orden jerárquico de los matrimonios, siendo la primera esposa quien por posición y edad ocupa un lugar más destacado respecto a una segunda o tercera esposa. En ocasiones estas relaciones son de celos y competencia, como en Xala (1974), cuya trama se desarrolla en torno a una maldición de impotencia para un maduro hombre de negocios que, para subrayar su africanidad en la era de la descolonización, decide contraer matrimonio con una joven tercera esposa. En esta película, y en otros trabajos, Sembène se muestra contrario a la práctica de la poligamia ${ }^{4}$.

Ha sido sin embargo en sus últimas películas, Faat Kiné (2000) y Moolaadé (2003), en las que observamos cómo la mujer se convierte en protagonista absoluta, en heroína que se revela contra la dominación impuesta y que es capaz de marcar un nuevo rumbo en su comunidad (Akudinobi, 2006: 177-194). En cierto modo, podemos decir que comienza la producción feminista de Sembène, consciente de la gran importancia de la mujer en el futuro de África. En la primera de estas películas, la actriz Venus Seye encarna a Faat Kiné, una mujer con independencia económica y sexual, que ha criado sola a sus hijos ante el sucesivo abandono de sus respectivos padres. Una mujer moderna, urbana, de fuerte carácter y voluntad, que desde el entorno hostil de los valores patriarcales ha superado los obstáculos para convertirse en un

4 Este fue el tema precisamente de uno de sus primeros documentales cinematográficos, titulado Traumatisme de la femme face a la polygamie (1969). 
modelo de mujer africana del siglo XXI. Moolaadé, la última película de Ousmane Sembène, describe la lucha de una mujer africana en el seno de su sociedad por erradicar el ritual de la ablación. Al mismo tiempo, es una excelente presentación de la realidad africana desde África, sin la intermediación paternalista del primer mundo, tan detestada en África por las reminiscencias de los discursos colonialistas. La malí Fatoumata Coulibary, actriz y militante contra la ablación, encarna el papel de la protagonista, Collé Ardo, en una interpretación magistral que transmite humanidad, fortaleza y convicción. Representa la resistencia activa contra la mutilación genital femenina dentro de la comunidad o aldea, fundamental para el éxito de otros esfuerzos de erradicación procedentes de la esfera política. En este sentido, la lucha contra la mutilación en nuestros días refleja el empoderamiento de muchas mujeres africanas $^{5}$, rompiendo el tabú y secretismo que subyace a esta tradición ${ }^{6}$. En Moolaadé, Sembène muestra una profunda admiración por las mujeres africanas y recoge las diferentes voces en torno a la mutilación genital femenina como una manifestación de la lucha por el poder entre distintas instancias, una de las cuales es la de las purificadoras, que tratan de preservar su estatuto privilegiado. La postura del cineasta en este aspecto es muy compleja, pues para este escritor y director comprometido con la opresión y la desigualdad, las mujeres africanas viven dentro de un orden social basado en el principio de dominación masculina, pero consigue alejar la imagen de sujeto pasivo, victimizado. Supera los discursos que ignoran o invisibilizan el protagonismo de las mujeres africanas en la lucha contra la mutilación genital femenina y su diversidad de matices y muestra a una mujer africana activa, fuerte, inteligente, abastecedora de la supervivencia de la familia. En este sentido, Sembène presenta una seria y rigurosa trayectoria hacía la crítica feminista postcolonialista. Así, la película, realizada cuando Sembène cuenta con ochenta años, incluye algunas novedades que nos interesan resaltar. La primera es respecto a su producción, que a diferencia de las anteriores no es únicamente senegalesa, sino que cuenta con la participación económica de un gran número de países africanos. Además fue rodada en Burkina Faso, en lengua bamana ${ }^{7}$. Por otra parte, la crítica al colonialismo queda aquí en un registro poco representativo respecto a su filmografía anterior pues, en este caso, se centra en cuestionar una tradición propia de algunas sociedades africanas, la práctica de la mutilación genital femenina. En cierto modo, y aunque el cine de Sembène alcanza una dimensión universal, al incidir en la desigualdad y la opresión, se apre-

5 En este sentido, podemos indicar relevantes ejemplos de empoderamiento de mujeres africanas que luchan contra la mutilación genital femenina y que son reveladores de la transformación que están viviendo estas sociedades. Es el caso de Olayinka Koso Thomas, nigeriana, que recibió el premio Príncipe de Asturias en 1998 por su compromiso con la prohibición de la mutilación genital femenina; Stella Obasanjo, Primera Dama de Nigeria, que hizo una declaración oficial de "Cero Tolerancia contra la mutilación genital femenina», durante la conferencia organizada por el Comité Inter-africano sobre Prácticas Tradicionales que Afectan la Salud de las Mujeres y los Niños (IAC); Ellen Johnson Sirleaf, presidenta de Liberia; Nyamko Sabuni, nacida en Burundi, ministra sueca de Integración e lgualdad de Género desde hace cuatro años, y miembro del Partido Liberal, una inmigrante africana en la esfera pública de la Europa del siglo XXI; Rama Yade, de origen senegalés y secretaria de Estado para el deporte en Francia; o Mama Samateh, gambiana afincada en Barcelona y fundadora de la Asociación Mujeres Anti-Mutilación (AMAM), que defiende la sensibilización contra la mutilación genital femenina.

6 Podemos señalar como ejemplo la historia de la modelo Waris Dirie, que fue llevada recientemente a la gran pantalla por la cineasta a Sherry Hormann con el título La flor del desierto (Desert flower, 2009).

7 La lengua bamana forma parte del grupo mandé y no solamente es hablada por la etnia de los bamana o bambara sino que es también una lengua interétnica que supera los diez millones de hablantes en Malí Guinea, Burkina Faso y Senegal. Sembène se ha caracterizado por no aceptar la hegemonía de la francofonía en su cine y rodar muchas de sus películas en lenguas senegalesas, como el wolof y el diola. 
cia un esfuerzo por lograr una gran repercusión en África Occidental ${ }^{8}$ y encontrar elementos culturales comunes en esta región, para abarcar la diversidad cultural y étnica sobre la que se asienta la mutilación genital femenina.

\section{PROBLEMÁTICA EN TORNO A LA MUTILACIÓN GENITAL FEMENINA}

Hablar de mutilación genital femenina en África es un tema tabú, por lo que la elección del mismo para una película es una decisión valiente y llena de complicaciones. Sembène se posiciona con rotundidad en contra de la práctica de la mutilación, pero refleja la compleja variedad de posiciones en torno a la misma presentes en la sociedad africana, sin silenciar las voces discordantes ni los conflictos ideológicos internos, y considera que es la propia sociedad africana la que tiene que liberarse de toda injerencia y delimitar su cultura, eliminando aquellos elementos y tradiciones injustas, opresivas, dañinas. La OMS, en la Nota descriptiva $n^{\circ} 241$ de febrero de 2010, define que la mutilación genital femenina ${ }^{9}$ (MGF) comprende todos los procedimientos consistentes en la resección parcial o total de los genitales externos femeninos, así como otras lesiones de los órganos genitales femeninos por motivos no médicos ${ }^{10}$. Actualmente la lucha internacional contra la mutilación genital femenina, en la que participan multitud de organizaciones internacionales como la OMS, UNICEF, UNIFEM, UNWOMAN, etc., a menudo adopta un matiz que se percibe a modo de injerencia colonial, pues refleja a la mujer africana victimizada, pasiva, inculta, supersticiosa, que precisa ser salvada por la cultura occidental, dotada de valores superiores. En este sentido, siguiendo a Spivak, la criminalización internacional de la mutilación genital femenina se percibe como otro ejemplo de cómo «los hombres blancos están salvando a las mujeres de piel morena de los hombres de piel morena» (Spivak, 2009: 95). Spivak ha denunciado que el discurso occidental construye a una «monolítica-mujer-delTercer-Mundo» como sujeto subalterno, de manera que esta mujer-víctima de la mutilación queda ubicada en la otredad. En la misma línea, Chandra Mohanty ha analizado la construcción de la «mujer del Tercer Mundo» como sujeto monolítico singular en el discurso humanista de Occidente y sugiere que algunos escritos colonizan de forma discursiva las heterogeneidades materiales e históricas de las vidas de las mujeres del Tercer Mundo (Mohanty,

8 También ha sido excepcional su difusión en nuestro país, en el que el cine africano nada contracorriente. Moolaadé ha sido emitida en televisión, proyectada en numerosos ciclos y comercializada en DVD en nuestro país por Cameo media. Por su calidad y por su planteamiento, Moolaadé, constituye en sí una invitación al cine africano, pero sobre todo es una película capaz de cambiar el mundo, allí para tomar conciencia de los daños de la ablación y aquí para despertar nuestro interés y respeto por África.

9 Emplearemos en este texto la denominación mutilación genital femenina (MGF) frente a otras denominaciones como ablación o «purificación» para referirnos a una práctica que consideramos muy negativa, pero que consideramos necesario abordar desde una perspectiva antropológica que nos permita comprender la diversidad de comportamientos de la familia humana sin su demonización etnocéntrica.

10 Además la OMS establece cuatro tipologías básicas: 1) clitoridectomía: resección parcial o total del clítoris (órgano pequeño, sensible y eréctil de los genitales femeninos) y, en casos muy infrecuentes, solo del pliegue de piel que rodea el clítoris; 2) excisión: resección parcial o total del clítoris y los labios menores, con o sin excisión de los labios mayores; 3) Infibulación: estrechamiento de la abertura vaginal para crear un sello mediante el corte y la recolocación de los labios menores o mayores, con o sin resección del clítoris; y 4) todos los demás procedimientos lesivos de los genitales externos con fines no médicos, tales como la perforación, incisión, raspado o cauterización de la zona genital. 
2008). También en el pensamiento africano existe un foco predominante de crítica postcolonialista, con la escritora ghanesa Ama Ata Aidoo, la escritora nigeriana Flora Nwapa, Filomina Chioma Steady, o Anthonia Kalu, que denuncia cómo se estigmatiza a las diferentes culturas africanas $y$, tras una actitud paternalista, se unifica a todas las mujeres africanas dentro del papel de víctimas. Los movimientos de mujeres africanas, con líneas de pensamiento muy diversas, coinciden en la idea de que ha sido el periodo colonial el que ha introducido o fortalecido en África la desigualdad entre hombres y mujeres. Frente a la criminalización internacional de la mutilación genital femenina a través de numerosos protocolos y tratados internacionales, además de su tipificación como delito en numerosas legislaciones nacionales del panorama internacional, el objetivo de este apartado es realizar una aproximación al pensamiento intelectual africano que permita comprender la perspectiva postcolonialista del cine de Sembène, el protagonismo de la mujer en la lucha por la abolición de las tradiciones perjudiciales y la postura de los movimientos de mujeres africanas en torno a la mutilación genital femenina. El pensamiento intelectual africano sostiene que la situación de las mujeres africanas está principalmente afectada por las consecuencias de la situación colonial vivida en el continente africano y por factores de raza y clase social. También se muestran preocupadas especialmente por las consecuencias del nuevo capitalismo globalizador que ha dejado el proceso descolonizador y sus efectos en la estructura y organización de las sociedades tradicionales africanas ${ }^{11}$. En la actualidad, podemos señalar tres elementos principales de fricción que denuncian numerosas intelectuales y pensadoras africanas que permiten comprender su particular posición en torno a la lucha internacional contra las mutilaciones genitales. Uno de ellos es la creencia común de que la desigualdad en las sociedades africanas es una consecuencia del colonialismo. Incluso algún sector intelectual africanista sostiene que la categoría de género es una construcción occidental cuya presencia en África es consecuencia del proceso de transformación de la sociedad africana, derivado del colonialismo y de la globalización mundial (Vieitez, 2005: 34). En segundo lugar, la crítica general al eurocentrismo presente en algunos de los postulados feministas occidentales que rechazan el papel tradicional de la mujer en la familia y con los que las mujeres africanas no se sienten representadas ${ }^{12}$. Finalmente, otra de las críticas se centra en la visión monolítica, victimizada y estereotipada de la mujer africana, con la que tampoco se identifican ${ }^{13}$. En cierto modo podemos comprender la percepción africana de que la lucha occidental contra la mutilación genital femenina es una nueva forma de colonialismo cultural. En este sentido se ha pronunciado Anouk Guinee, que sostiene la necesi-

11 El efecto de la globalización y el capitalismo en la estructura agraria africana tradicional produce una nueva situación de dependencia, la mujer pierde el control de los recursos productivos básicos como consecuencia de la economía de mercado. La agricultura se transforma y las explotaciones agrícolas son trabajadas por mano de obra asalariada masculina reclutada según el modelo de división del trabajo occidental, relegando a la mujer al trabajo doméstico o al sector informal de la economía. Además, como señala Algora Weber, se sustituyen los cultivos de consumo interno por cultivos destinados a la exportación (Algora, 2003, 179-190).

12 Como denuncian Catherine Obianuju o la senegalesa Mariama Bâ, que ofrecen planteamientos alternativos para analizar las relaciones de género que parten de las costumbres africanas tradicionales.

13 Filomina Chioma Steady advierte que la mujer africana nunca ha sido un ser pasivo ni apolítico. Oyèrónké Oyèwumi, señala que las aspiraciones de la mujer occidental eran un valor existente ya en las sociedades africanas pre-coloniales, donde los papeles sociales eran flexibles y no dependían del sexo biológico. Esta imagen es también cuestionada por la escritora ghanesa Ama Ata Aidoo o la escritora nigeriana Flora Nwapa, al igual que otras críticas feministas postcolonialistas como Chandra Mohanty o Spivak. 
dad de erradicar la excisión por no ser en ningún caso éticamente defendible, pero considera infructuosa cualquier estrategia que se perciba como una manifestación de la opresión de raza, considerando fundamental diseñar un plan de acción que no fomente las desigualdades de raza y género (Álvarez, 2001: 120). Una vez introducidas estas puntualizaciones se pueden indicar las diversas posturas en torno a la mutilación genital femenina que presiden las diferentes maneras de luchar contra la misma por parte de los movimientos africanos de mujeres. Así, una primera postura es la adoptada por los movimientos de mujeres africanas contrarios a estas mutilaciones, pero que rechazan el protectorado de las feministas del primer mundo por su tratamiento etnocéntrico de las culturas africanas. Una segunda posición es la de un sector de mujeres africanas, defensoras de la tradición de la mutilación genital femenina, que se centran en la crítica postcolonial y entienden que la lucha de las mujeres occidentales contra la misma supone una injerencia en sus tradiciones culturales, una nueva forma de imperialismo intelectual y un neocolonialismo cultural. Un tercer sector niega que la mutilación genital femenina se asocie a la opresión sexual y a la privación del placer, preocupándose en cambio por la salud de las mujeres mutiladas. Se muestra a favor de regular y medicalizar su práctica, rechazando los argumentos del feminismo occidental a favor de la erradicación, que consideran obsesionado con la sexualidad más que en la salud. Estas pensadoras denuncian el efecto perverso de la prohibición de esta práctica por los gobiernos coloniales y las iglesias cristianas radicadas en territorios colonizados desde principios del siglo $X X$, que ha supuesto el incremento de infecciones derivadas de su práctica encubierta, la obtención de mayores recompensas económicas por parte de las purificadoras derivada de las dificultades añadidas por la clandestinidad y la adopción de la mutilación genital femenina como una seña de identidad por parte de los movimientos independentistas como reacción a los esfuerzos por erradicarla (Velasco, 2007). Esta postura, que se centra en la salud y no en la opresión sexual, no condena la mutilación genital, sino que trata de luchar contra las infecciones y muertes que conlleva, proponiendo como solución su medicalización. En 1985, en la Conferencia de Naciones Unidas de Nairobi, se inauguró el Movimiento de Mujeres Africanas que se basaba en la lucha de los movimientos feministas europeos y anglosajones. Sin embargo, la diversidad de posturas de los movimientos feministas africanos actuales aparece sugerentemente recogida en la Carta de Principios Feministas para las Feministas Africanas acordada en el Foro Feminista Africano (AFF) de 2006, celebrado en Accra (Ghana). En este documento reconocen que no tienen una identidad homogénea, sino que el reconocimiento de la diversidad y el compromiso de transformar la sociedad africana y liberarla de todas las formas de opresión y explotación patriarcal constituye su común denominador. El documento recoge también, como reflejo de la crítica postcolonial, la imbricación del patriarcado con otras estructuras opresoras globales capitalistas de clase, raza, etnia o religión, lo que marca una gran diferencia con los movimientos feministas occidentales. Estos movimientos luchan por el fin de la opresión patriarcal y todas sus manifestaciones. Entre los principios recogidos en el documento de Accra incluyen la «libertad de elección y autonomía con respecto a los temas de integridad física, incluyendo derechos reproductivos, aborto, identidad sexual y orientación sexual», dando cabida así a la postura de aquellos movimientos de mujeres africanas que no persiguen erradicar el ritual, sino su práctica insalubre o su imposición a la fuerza, defendiendo la practica de la mutilación genital femenina consentida voluntariamente en mujeres mayores de edad. Entre las numerosas organizaciones africanas implicadas en la lucha contra las 
mutilaciones genitales podemos mencionar el Inter African Comitee (IAC), que en 1984 creó una red de organizaciones con la finalidad de erradicar las prácticas tradicionales «nefastas» ${ }^{14}$, y Equality Now, que en el año 2000 creó un fondo contra la mutilación genital femenina con el fin de financiar a organizaciones implicadas en abolir esta práctica ${ }^{15}$.

\section{GÉNERO Y VIOLENCIA EN EL UNIVERSO SIMBÓLICO DE MOOLAADÉ}

La acción de Moolaadé transcurre durante cinco días en una pequeña aldea tradicional agrícola en la que el Islam convive con la tradición animista. La principal línea argumental es la petición de asilo o «protección» (moolaadé) a la protagonista por parte de un grupo de niñas aterradas por el rito de ablación a la que deben ser sometidas para ser aceptadas socialmente como mujeres. Piden protección a Collé Ardo (Fatoumata Coulibary) quien, consciente de los peligros para la salud, había conseguido salvar de la mutilación genital a su propia hija unos años atrás. Mientras dura la sagrada institución de la protección del moolaadé, la vida de la aldea gira en torno al debate sobre esta práctica y su significación social. De este modo entran en escena todos los discursos implicados en el ritual, que es lo mismo que dar voz a todos los grupos que forman la comunidad. La ceremonia, inserta en una sociedad patriarcal presidida por el principio de dominación masculina, es un ritual practicado por las propias mujeres, como guardianas de su tradición cultural. En la película, las mujeres aparecen representadas en el ámbito doméstico, en el pozo y en el bosque ceremonial (todos ellos espacios culturalmente asignados a las mujeres), pero también en la plaza de la asamblea (espacio público) en donde elevan al consejo de ancianos sus quejas y reivindicaciones y donde el poder patriarcal reafirma su discurso conservador, argumentando la autoridad de las tradiciones locales y de la imposición coránica. La heroína de la película, Collé Ardo, toma conciencia de lo nefasto de la ablación por su propia experiencia en el difícil parto de su hija Amsatou, y en dos partos anteriores fracasados. Uno de los efectos perjudiciales de la mutilación genital femenina es el aumento del riesgo de muerte tanto para la madre como para su bebé. Asimismo, ha sido testigo de la muerte de varias niñas desangradas en la ceremonia. El único apoyo que tiene la protagonista es la radio, en donde escucha campañas contra la mutilación e incluso opiniones contrarias procedentes de algunos imanes islámicos. Frente a Collé Ardo, y a las mujeres que paulatinamente se sumarán a su causa (Rapfogel y Porton, 2004, 20-25), el resto de las mujeres de la aldea defienden los tradicionales valores conservadores. Estos valores están representados en el grupo de las «purificadoras» o salindana, esto es, las sacerdotisas que dirigen los rituales de paso de las niñas ${ }^{16}$. Sus esfuerzos por conservar sus privilegios se justifican a través de la defensa de la tradición. Una tradición que impide considerar adulta (socialmente) a una mujer no «purificada» ${ }^{17}$ y, por lo tanto, excluida del matrimonio. Así, la importancia de

14 Entre las llamadas tradiciones nefastas, las que especialmente perjudican a la mujer son, además de la mutilación genital femenina, los matrimonios forzados y los rituales de viudedad.

15 Equality Now celebra una reunión anual de beneficiarios del Fondo. En 2004 celebró en Nairobi la primera reunión internacional de antiguas purificadoras.

16 La posición social de las purificadoras y los privilegios que le son inherentes es una de las dificultades añadidas para la erradicación de la mutilación genital femenina en la actualidad.

17 Esta idea de pureza asociada a la mutilación genital femenina nos remite a Mary Douglas que señala cómo la cultura mediatiza las experiencias de los individuos y provee unas categorías básicas y configuraciones positivas (Douglas, 1991: 39). Al considerar la sexualidad de la mujer peligrosa para el orden social se recurre al simbolismo a través de las ideas de contaminación y tabú o a otras asociaciones negativas frecuentemente alimen- 
este ritual es precisamente la construcción social de esa categoría social ${ }^{18}$. La consecuencia es la creación marginal de otra categoría socialmente desprestigiada y rechazada: la de la mujer no circuncidada, no purificada. Una bilakoro en Malí (o una solima, en Gambia y Senegal) es aquella mujer que no ha pasado por la mutilación y es socialmente considerada sucia, impura, contaminada ${ }^{19}$. Para la sociedad la mutilación genital es un ritual de purificación, confiere honorabilidad y eleva a las niñas a una nueva categoría social: mujeres puras y aptas para el matrimonio y la maternidad. Sólo a través del rito de la mutilación y a partir del matrimonio una mujer adquiere un rol social y los recursos necesarios para subsistir ${ }^{20}$. En cierto modo, desde el punto de vista social el tema de la mutilación genital femenina no puede desligarse del matrimonio.

En la película, Sembène recrea magistralmente el punto de vista masculino en torno al matrimonio desde varias perspectivas. Por un lado, el jefe de la aldea y el consejo de ancianos, así como el griot, reproducen el discurso androcéntrico de jerarquía sexual, por el cual jamás se casarían con una bilakoro y consideran una rebelión contra las buenas costumbres (animistas e islámicas) y el orden social la revuelta emprendida por Collé Ardo. Otros puntos de vistas nos ofrecen lo que podríamos denominar nuevas masculinidades. Por una parte, la opinión contra los matrimonios forzados (especialmente de menores), esto es, fuera de las tradicionales alianzas familiares, que aparece en boca de aquellos personajes «externos» al sistema social de la aldea. Estos discursos corresponden al «mercenario», un vendedor ambulante, antiguo soldado que ha viajado por numerosos países, que considera pederastas a los aldeanos. Es también el caso del hijo del jefe, Ducuré, que acaba de llegar de París después

tadas por mitos. Así, en un repaso por la mitología africana encontramos prescripciones directas de la ablación en algunas cosmogonías. A modo de ejemplo podemos citar el mito dogón que considera el clítoris como un atributo masculino o el mito bambara según el cual el clítoris es el hogar de un espíritu maligno. En la comunidad reflejada en Moolaadé la mutilación genital femenina se basa en las ideas de contaminación y pureza. La sexualidad de la mujer se considera un peligro para la comunidad y la respuesta social es la eliminación de una importante zona erógena antes de su primera menstruación. El refuerzo que dota de eficacia a la norma se basa en la amenaza de contaminación que representa aquella mujer que burla la prescripción de la mutilación genital femenina. Pero es principalmente la asociación de la «purificación» con otra institución, el matrimonio, la que le otorga su mayor eficacia.

18 Es interesante resaltar el uso de las diferentes formas de referirse al ritual por parte de los distintos personajes que protagonizan la historia. Así, mientras que Sembène utilizaba la terminología que se ha ido forjando por parte de la crítica internacional, según la cual estamos ante auténticas mutilaciones y por tanto se refiere a ella como mutilación genital femenina, en cambio, en la película se puede distinguir una doble terminología para referirse a esta práctica: el uso de salindé, que es una palabra mandinga que se refiere a la ablación como una purificación y la utilización del descriptivo término «cortar» o «corte» en el que insisten las niñas que invocan la protección del moolaadé (Nochimson, 2010). Este doble uso lingüístico revela la dicotomída entre la acción física y la acción simbólica. Las niñas que huyen de la ablación, aún no iniciadas, se refieren al acto físico del corte, de la ablación, excisión o cutting. En cambio para la sociedad adulta, y para la propia encargada de la práctica del ritual, la purificadora -salindana-, la acción ritual va más allá del acto físico y está dotado de un significado simbólico socialmente construido.

19 La sociedad bambara (Malí) cree que el contacto del clítoris con el pene produce la muerte del hombre o que puede provocar la muerte del bebé por el contacto con su cabeza. De esta manera la transgresión de la norma, la oposición de una mujer a ser mutilada o de una madre a mutilar a su hija, supone su exclusión social, genera actitudes de evitación social y dificulta sus posibilidades de contraer matrimonio.

20 Para comprender la fuerza de estas categorías es preciso señalar «la importancia del matrimonio como parte integral de la estructura social en África. Los individuos sólo son considerados, personas completas, cuándo están casados y con descendencia» (Rodríguez, 2002: 81-82). 
de trabajar como emigrante varios años ${ }^{21}$, quien influido por las costumbres occidentales desafía la autoridad de su padre y aspira a un matrimonio por amor con Amsatou, la hija no "purificada» de la rebelde Collé Ardo. Estos personajes, que nos ofrecen un contrapunto al discurso masculino dominante, tienen un final trágico. Ducuré es desheredado y repudiado por su padre y el «mercenario» acaba siendo asesinado por defender a la protagonista cuando públicamente está siendo azotada por su marido para que ponga fin al asilo o protección de las niñas. Cire Bathily, el marido de la protagonista22, es obligado a castigar la insubordinación de su mujer por la presión social, sobre todo por la autoridad que sobre él ejerce su hermano mayor. No obstante este personaje es relevante porque nos muestra un cambio de actitud, pues acaba arrepentido de su conducta, enfrentándose a los hombres de la aldea y aceptando las tesis de Collé Ardo.

La fuerza de los diálogos se combina en Moolaadé con algunos símbolos visuales de gran potencia. La cultura africana sigue su propia historia, su propia evolución. La mujer africana impulsa, contracorriente, nuevos valores sociales que gracias a la lucha cotidiana se consolidan y contribuyen a construir una sociedad más justa. Una de las escenas más líricas y con mayor simbolismo de la película nos muestra en el mismo plano tres elementos altamente representativos. En primer lugar, el ancestral termitero sagrado, que simboliza las costumbres animistas, a través de las cuales perviven algunos valores necesarios para el futuro de la comunidad, como la solidaridad y la protección, pero también otras instituciones que deben ser cuestionadas. Al lado aparece una característica mezquita sudanesa, pequeña, de adobe con los extremos de las vigas a la vista, que representa el arraigo del Islam en el África Occidental. Representa la fusión de rasgos culturales derivada de la expansión del Islam, y también su función como instrumento de control social. Una tercera construcción aparece en este escenario. Es una montaña de radiotransmisores que los hombres han confiscado a las mujeres con el fin de aislarlas de cualquier elemento perturbador del orden establecido. Mediante la metáfora visual, Sembène refuerza la idea del cambio social. En el plano final de la película, un centenario huevo de avestruz que corona la cúpula de la mezquita se transforma en una antena de televisión. En Moolaadé, el valor de la protagonista arrastra al resto de madres a tomar una nueva actitud de rechazo al ritual de la ablación. Esta postura solamente es posible con una profunda transformación social en la que participen hombres y mujeres. El cine, la radio, la televisión y otros medios audiovisuales (los nuevos griots) son necesarios para cambiar la sociedad. Con Moolaadé, Sembène pretende sensibilizar al público africano, al que va dirigida, de la necesidad de abandonar la práctica de la mutilación genital femenina. A los espectadores occidentales, Sembène nos muestra un África llena de vida, belleza y dignidad que afronta este reto por sí misma.

21 Ducuré trae en su equipaje de regreso el extrañamiento que ahora le produce su propia cultura, lo observado en su proceso migratorio favorece los cuestionamientos y la reflexión sobre los propios modelos sociales. Este personaje refleja la estrategia familiar senegalesa en el proceso transnacional de la migración, que es fundamentalmente de carácter masculino por la que se selecciona en origen a aquellos varones con más probabilidades de éxito (Nash, 2005).

22 Collé Ardo es la segunda esposa de las tres con quien tiene matrimonio Cire Bathily. Si bien ya hemos señalado la posición contraria a la poligamia en Ousmane Sembène, en Moolaadé la relación entre las esposas es presentada como un marco de cooperación y solidaridad. La solidaridad de Hadjatou, primera esposa, con la protagonista respectivamente de Cire Bathily supone el inicio de la revolución en la aldea respecto a la «purificación». 


\section{BIBLIOGRAFÍA}

AKUDINOBI, Jude G (2006), «Durable Dreams: Dissent, critique and creativity in Faat Kiné and Moolaadé», Meridians. Feminism, Race, Transnationalism, 6, pp. 177-94.

ALGORA WEBER, M. D (2003), «La Historia contemporánea en África y sus efectos sobre las mujeres en la sociedad subsahariana», Cuadernos de Historia Contemporánea, 1, pp. 179-190.

ÁLVAREZ DEGREGORI, M. C. (2001), Sobre la mutilación genital femenina y otros demonios, Barcelona, Universidad Autónoma de Barcelona.

BUSCH, Annett y Annas, Max (2008), Ousmane Sembène: interviews, UP of Mississippi.

CHAM, Mbye Baboucar (1982), "Ousmane Sembene and the Aesthetics of African Oral Traditions», Africana Journal, 13.1-4, pp. 24-40.

DIOP, Abdoulaye Bara (1991), «La polygamie au Sénégal», Cinémaction, 34, pp. 51-54.

DOUGLAS, Mary (1991), Pureza y peligro. Un análisis de los conceptos de contaminación y tabú, Madrid, Siglo XXI.

GADJIGO, Samba et al. (eds.) (1993), Ousmane Sembene: Dialogues with Critics and Writers, Amherst, University of Massachusetts Press.

GADJIGO, Samba (2001), «Ousmane Sembène et le cinéma politique», Présence Francophone. Revue Internationale de Langue et de Littérature, 57, pp. 78-86.

GADJIGO, Samba (2004), "Ousmane Sembène and History on the Screen: A look back to the future», en PFAFF, Francoise (2004) Focus on African Films, Bloomington, Indiana UP, pp. 33-47.

- (2007), Ousmane Sembène, une conscience africaine: Genèse d'un destin hors du commun, París, Homnisphères.

GONZÁLEZ GARCÍA, Fernando (2009), «Historia del colonialismo en el cine africano subsahariano», Secuencias, 30, pp.11-33.

IJERE, Muriel (1998), «Sembene Ousmane et l'institution polygamique», Ethiopiques, 5. 1-2, pp. 173-184.

KAPLAN, Adriana (2003), "Procesos migratorios Senegambianos en Cataluña», en Mosaico de culturas, Barcelona, Museu Etnológic de Barcelona.

KAPLAN, Adriana y BEDOYA, Helena (2006), «Las mutilaciones genitales femeninas en España: una visión antropológica, demográfica y jurídica», en Lucas, J. de (coord.) (2006) Europa: derechos, culturas, Valencia, Tirant lo Blanch.

KAPLAN, E. Ann (ed.) (2000), Feminism and film, Oxford, Oxford UP.

Kindem, Gorham H. y Steele, Martha (1991), «Emitai and Ceddo: Women in Sembene's Films», Jump Cut, 36, pp. 52-60.

MCCAFFREY, Kathleen M. (1980), "Images of Women in West African Literature and Film: a Struggle against Dual Colonization», International Journal of Women's Studies, 3, pp. 76-88.

MOHANTY, Ch T. (2008), «Bajo los ojos de Occidente: academia feminista y discursos coloniales», en SUÁREZ NAVAZ, L. y HERNÁNDEZ CASTILLO, R. A. (eds.) (2008) Descolonizando el feminismo: Teorías y prácticas desde los márgenes, Madrid, Cátedra, pp. 117-163.

NASH, Mary (2005), Inmigrantes en nuestro espejo. Inmigración y discurso periodístico en la prensa española, Barcelona, Icaria. 
NIANG, Sada y GADJIGO, Samba (1995), «Interview with Ousmane Sembene », Research in African Literatures, 26:3, pp. 174-178

NOCHIMSON, Martha P. (2010), World on film: an introducction, Wiley Blackwell.

PFAFF, Françoise (1984), The Cinema of Ousmane Sembène, Westport, Greenwood.

- (1995), "Sembene, A Griot of Modern Times», en MARTIN, Michael T. (ed.) (1995) Cinemas of the Black Diaspora, Detroit, Wayne State UP, pp. 118-128.

- (1999), «Ousmane Sembène, el clásico de los clásicos», Nosferatu, 30, pp. 58-68.

- (2004), Focus on African Films, Bloomington, Indiana UP.

RAPFOGEL, Jared y PORTON, Richard (2004), "The Power of Female Solidarity: An Interview with Ousmane Sembene», (2004) Cineaste: America's Leading Magazine on the Art and Politics of Cinema, pp. 20-25.

RODRIGUEZ, Dan (2002), «Las mutilaciones genitales en la población senegambiana de Cataluña y África: El debate entre universalismo y relativismo cultural», en GonZÁLEZ ECHEVARRÍA, Aurora y MolinA, Luis (coords.) (2002) Abriendo surcos en la tierra. Investigación básica y aplicada en la UAB: Homenaje a Ramón Valdés, Bellaterra, UAB, pp. 79-102.

RUFA'l, Ahmed (1983), L'image de la femme africaine dans l'œuvre d'Ousmane Sembene, Université de Sherbrooke, (M.A.)

SPIVAK, G. Ch. (2009), ¿Pueden hablar los subalternos?, Barcelona, Museu d'Art Contemporari de Barcelona.

THIAM, A. (1983), «El combate de las mujeres por la abolición de las mutilaciones sexuales», La mujer y las esferas de poder. La política, la economía y los movimientos sociales. Revista Internacional de Ciencias Sociales, 25. 4, UNESCO, pp. 793-802.

VELASCO MAÍlLO, Honorio M. (2007), Cuerpo y espacio. Símbolos y metáforas, representación y expresividad de las culturas. Madrid, Ramón Areces.

VIEITEZ CERDEÑO, Ma Soledad (2005) «Antropología y género: Miradas desde África». Crítica, n 923, Madrid, pp. 32-35.

Quaderns, 7 (2011), pp. 55-66 